\title{
The Characteristics of Suction, Yield and Strength for the Unsaturated Intact Loess Based on True Tri-axial Tests
}

\author{
Jinjin Fang and Yixin Feng* \\ School of Civil Engineering, Henan Polytechnic University, Jiaozuo 454000, China \\ *Capital Construction Department, Henan Polytechnic University, Jiaozuo 454000, China \\ *Corresponding Author: 327256272@qq.com.
}

\begin{abstract}
Under the condition of measuring suction, there are few reports on the experimental study of unsaturated intact loess with true triaxial apparatus. In order to study the effect of intermediate principal stress and suction on the mechanical properties of unsaturated intact loess, a series of isotropic consolidation and shear tests with different intermediate principal stress ratio $b$ under constant water content were performed on intact loess with various initial suctions with the true tri-axial apparatus for unsaturated soil. The characteristics of suction, yield, and strength of unsaturated intact loess were studied. The results show that when the moisture content is relatively smaller, the suction decreases rapidly after isotropic consolidation, the suction decreases slowly while the water content is comparatively large, and the suction increases with the rise of $b$ value after shear. The yield suctions of unsaturated soils with different initial suction are identical, and the isotropic compressive yield stress increases with the increase of initial suction. The growth of net mean stress has a great influence on the bulk deformation of unsaturated soil before yield point, and the suction plays a major role in the bulk deformation of unsaturated soil after yield point. The shear strength of unsaturated soil is enhanced with the increase of suction. The amplitude of increase at low suction is greater than that at high suction. With the decrease of initial suction, the suction differences at shear failure become smaller and smaller under different net confining pressures.
\end{abstract}

Keywords: Strength; suction; true tri-axial apparatus; unsaturated intact loess; yield.

\section{INTRODUCTION}

Loess is mostly distributed in arid and semi-arid areas. The loess used in engineering is often located above the ground water level and in unsaturated state. The engineering properties of unsaturated soils are very complex. Therefore, the influence of suction must be focused on the research about the engineering properties of unsaturated soils. Aiming at the problem of strength and deformation of unsaturated soil, many scholars (Zhan et al.,2006; Liao et al., 2005; Zhang et al., 2009; Chen, 1999; Li et al., 2014; Li et al., 2018; Ng et al., 2016; Ng et al., 2017; Xing et al., 2016; Lin et al., 2007; Hu et al., 2005) have carried out a large number of experiments under different stress paths for remolded disturbed or undisturbed unsaturated soils by using unsaturated direct shear apparatus and unsaturated triaxial apparatus, and many valuable results have been achieved. A series of tests, such as moisture absorption tests, equal suction-compression-consolidation tests, and shear tests, on unsaturated expansive soil using unsaturated soil triaxial apparatus with control suction were performed. Their conclusions are that, in the process of low confining pressure and moisture absorption, obvious yield properties emerge in the volume change properties of compacted expansive soils (Zhan et al., 2006). Consolidated drained-direct-shear tests with controlled suction on unsaturated intact loess were carried out by using the improved unsaturated soil direct shear apparatus. It has been found that the relationship between shear stress and shear displacement is a kind of "weak hardening" type when the net vertical pressure is small, and a kind of "strong hardening" when the net vertical pressure is large 
(Liao et al., 2005). A series of triaxial tests were carried out using double-cell triaxial system for unsaturated soils to investigate the behavior of volume change, yield, and strength of unsaturated clays (Zhang et al., 2009). Based on an isotropic compression test with controlled suction, a triaxial shrinkage test with controlled net-mean stress, and a triaxial drained shear test with controlled suction and net cell pressure, Chen (1999) proposed a modified yield criterion associated with suction increase and suggested a new method to identify the yield stress under triaxial shear condition. Based on the conventional triaxial shear strength test, it has been proved that the water content is related to the strength of structural loess, and the water content and environmental pressure have significant effect on the stress-strain relationship of structural loess (Li et al., 2014). Filter paper technique, humidity control technique, and axis translation technique were used to study suction equilibrium time of unsaturated reticulate red clay. Test results show that suction equilibrium exists in both suction measurement or suction control using any technique in the tests, and the suction equilibrium time in measuring matric suction of unsaturated reticulate red clay with axis translation technique is shorter than that using filter paper technique ( $\mathrm{Li}$ et al., 2018). Compression and shear behaviors of intact loess and loosely compacted loess were investigated via unsaturated direct shear tests; despite significant volumetric strain upon wetting (up to 14\%), suction-induced volumetric shrinkage is less than $2 \%$ for all suction levels considered because of the as-compacted moisture content at the dry side of the optimum value. During shearing, all unsaturated tests dried to high suctions indicate a strain-softening mode of failure associated with noticeable dilation; for a given suction and temperature, intact specimens exhibit a higher shear stiffness and larger dilatancy than re-compacted specimens (Ng et al., 2016; $\mathrm{Ng}$ et al., 2017). Conventional triaxial CU tests with different moisture contents were utilized to obtain the effective steady state strength parameters and then the suction stress characteristic curves were obtained (Xing et al., 2016). Lin et al. (2007) investigated the shear strength behavior of unsaturated soils based on pressure plate test and direct shear test. A series of direct shear tests of undisturbed loess under controlled suction were carried out by means of unsaturated soil direct shear apparatus, and the strength characteristics of unsaturated undisturbed loess were discussed (Hu et al., 2005).

For most researches on unsaturated loess, experiments have been conducted under the condition of controlling suction with the remolded soil selected as the research object (Zhan et al., 2006; Zhang et al., 2009; Chen et al., 1999; Li et al., 2014; Li et al., 2018; Ng et al., 2016; Ng et al., 2017; Lin et al.,2007). In recent years, under the condition of measuring suction, the isotropic compression and triaxial shear tests on intact loess of different initial suction by using unsaturated soil triaxial apparatus were performed, and a lot of valuable conclusions were obtained with many factors being studied, such as the deformation characteristics, critical state, yield, and suction variation characteristics of unsaturated intact loess under constant water content. Nevertheless, only simulations have been conducted on the deformation law of soil under axisymmetric stress state (Chen et al., 2014). In the actual geotechnical environment, the 3 principal stresses of soil are often varied; most of the above researches do not consider the influence of intermediate principal stress on deformation, strength, and suction of the soil and cannot truly reflect the complex stress state of soil. However, there seem to be few researches of true triaxial tests on unsaturated intact loess under the condition of measuring suction, and the variation of suction with the intermediate principal stress parameters is rarely reported. Xie \& Feng (2006), with detailed theoretical analysis, pointed out that the suction of unsaturated soil can only be determined by the basic physical nature of the soil itself. If the suction of unsaturated soil is artificially controlled by changing pore water pressure or pore gas pressure, it will inevitably lead to the change of physical properties of the soil itself. Therefore, a series of tests to control the suction of unsaturated soil are proven not to be good methods. At present, the way of understanding the mechanical properties of soil at home and abroad has already exceeded the limitation of traditional testing instruments, as direct shear apparatus, unidirectional compression instrument, conventional triaxial apparatus, etc. Because of the advantages of reflecting the three-dimensional principal stress state of the soil unit, the true triaxial apparatus is recognized as the most complicated test instrument for simulating the stress condition. Moreover, a great deal of projects, such as embankment, earth dam and fill construction, foundation, and cavern engineering, are all involved in the change of the intermediate principal stress. Therefore, in order to simulate the three-dimensional principal stress state of soil without changing the physical properties of soil itself, and with the condition of measuring suction, this paper takes the intact loess of Xi'an as the object of study, carries out a series of isotropic consolidation and shear tests of different intermediate principal stress parameters $b$ on unsaturated 
intact loess of different initial suction under constant water content, studies the relationship between initial suction and saturation of unsaturated intact loess, and explores the yield stress, the yield suction, the suction, and strength change of unsaturated intact loess. The research results of this paper have important theoretical significance for the construction of unsaturated loess.

\section{TEST SCHEMES AND METHODS \\ Test soil samples}

The soil samples are $\mathrm{Q}_{3}$ intact loess from the Yue Deng-ge in the city of Xi'an; the depth of soil is $8 \mathrm{~m}$ below the surface. The soil samples are yellowish-brown, and the soil samples are taken from the same site and depth. The samples with dry density difference of less than $0.01 \mathrm{~g} / \mathrm{cm}^{3}$ and natural moisture content difference of less than $1 \%$ are cut into rectangular specimens of $7 \mathrm{~cm} \times 7 \mathrm{~cm} \times 14 \mathrm{~cm}$, for a total of 80 samples, and their physical properties, are shown in Table 1.

Table 1. Physical parameters of loess.

\begin{tabular}{|c|c|c|c|c|c|c|}
\hline $\boldsymbol{w}_{\mathbf{0}}(\%)$ & $\boldsymbol{\rho}_{\mathrm{d}}\left(\mathrm{g} \cdot \mathbf{c m}^{-3}\right)$ & $\boldsymbol{d}_{\mathrm{s}}$ & $\boldsymbol{e}_{\mathbf{0}}$ & $\boldsymbol{w}_{\mathrm{L}} / \mathbf{\%}$ & $\boldsymbol{w}_{\mathrm{p}} / \%$ & $\boldsymbol{I}_{\mathrm{P}}$ \\
\hline 15.6 & 1.35 & 2.7 & 1.007 & 31.67 & 20.91 & 10.76 \\
\hline
\end{tabular}

\section{Test equipment and test methods}

The test adopts true triaxial apparatus developed by the institute of Institute of Geotechnical Engineering of Xi'an University of Technology, as shown in Figure 1. Compared with the conventional triaxial instrument, the biggest advantage of this device is that the three axes can be used to obtain different principal stresses and strains. It can actually simulate the principal stress state of soil and test the mechanical characteristics of soil under different stress paths. Aiming at the requirement of unsaturated soil test under true triaxial stress condition, this paper has modified the main part of the true triaxial instrument. That is, based on the automatic control of original three-way principal stress, the pore air pressure and pore water pressure control and measuring devices are supplemented to accurately control and measure matric suction by using the axial shift technique, as shown in Figure 2(a) (b). Moreover, the sensor with higher precision will be used to measure the deformation of cuboid specimen in three directions independently and accurately. The pore air pressure $u_{\mathrm{a}}$ is applied through the plastic porous plate at the top of the sample. The lower end of the sample is directly contacted with a high air inlet value clay plate, which can realize that the pore water pressure $u_{\mathrm{w}}$ is measured directly through an external pressure sensor. The pore air pressure minus pore water pressure $\left(u_{\mathrm{a}}-u_{\mathrm{w}}\right)$ is matric suction. For specific equipment structures and functions see Shao et al. (2009). Then the formula for matric suction can be described as follows:

$s=u_{\mathrm{a}}-u_{\mathrm{w}}$

where:

$s$ : Matric suction;

$u_{\mathrm{a}}$ : Pore air pressure;

$u_{\mathrm{w}}$ : Pore water pressure. 


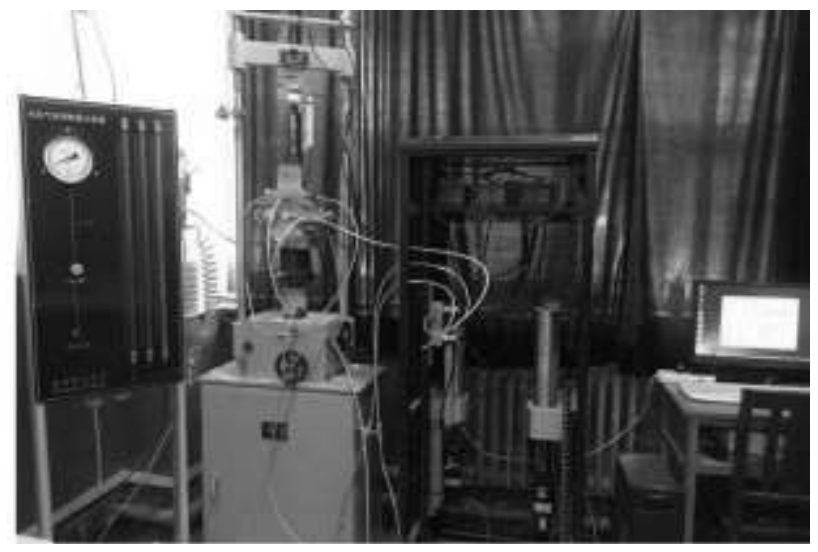

Fig. 1. True triaxial apparatus for unsaturated soil.

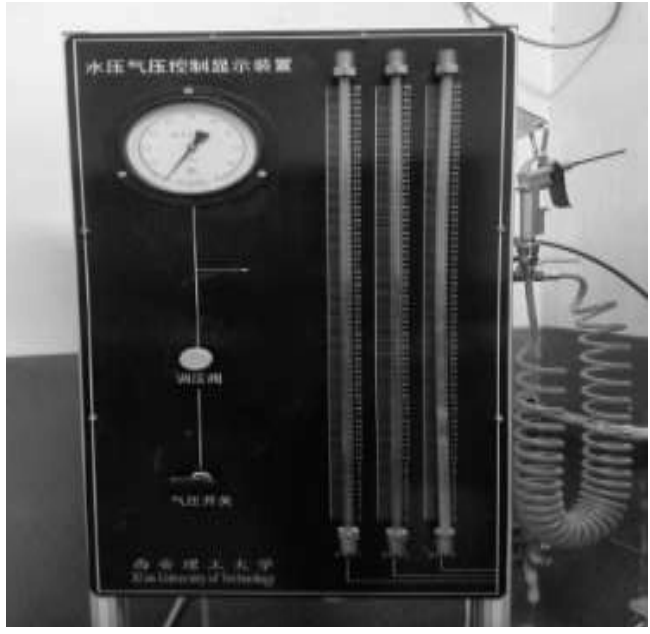

(a) Air pressure control system

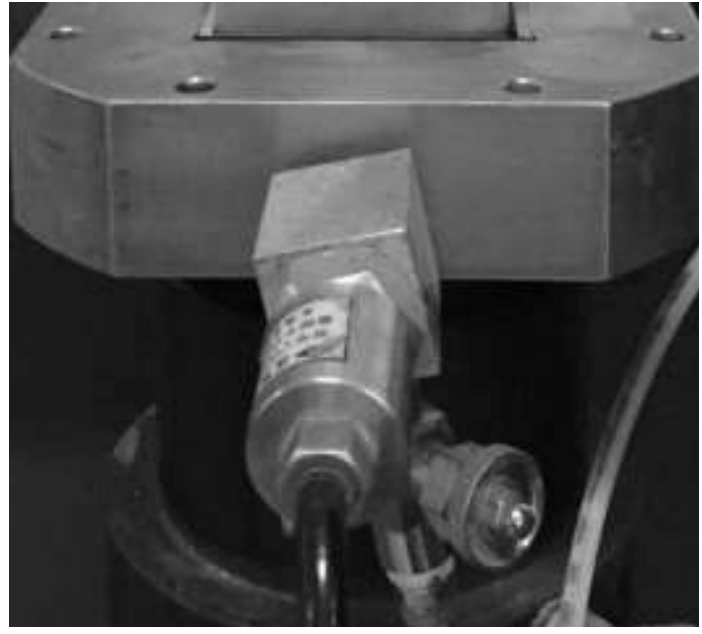

(b) Pore pressure sensor

Fig. 2. Pore air pressure and pore water pressure measuring device.

In this test, with means of humidification or dehumidification, samples dry density difference of less than 0.01 $\mathrm{g} / \mathrm{cm}^{3}$ and natural water content difference of less than $1 \%$ were formulated into $12.8 \%, 16.1 \%, 17.8 \%$, and $20.3 \%$, respectively, a total of four different moisture contents. The air-drying method is used for the samples below the natural moisture content, and the spray sprinkling method is used for the samples above the natural moisture content. After reaching the required moisture content of the preparation, it shall be placed in a moisturizing tank for more than 96 hours to ensure uniform moisture diffusion.

The constant moisture content tests are performed, which consist of three stages: the measurement of initial suction, the true triaxial isotropic consolidation, and the shear tests under different $b$ values. The initial suction of soil is measured by axial translation technique under the condition of no stress. In order to avoid cavitation, the air pressures with $500,300,200$, and $100 \mathrm{kPa}$ are applied to the samples with water content of $12.8 \%, 16.1 \%, 17.8 \%$, and $20.3 \%$, respectively. The criterion for initial suction stability is that the variation of suction is less than $0.5 \mathrm{kPa} / \mathrm{h}$. The isotropic consolidation net confining pressure $\sigma_{3}$ is $50,100,200,300 \mathrm{kPa}$, respectively, and the unsaturated soil is consolidated for 24 hours. In this paper, the compression stability criteria are shown as follows: the increment of external deformation is less than $0.005 \mathrm{~mm} / \mathrm{h}$ and the variation of suction is below $0.5 \mathrm{kPa} / \mathrm{h}$. The test adopts strain 
control, with the shear rate being $0.005 \mathrm{~mm} / \mathrm{min}$, and the intermediate principal stress parameter $b$ is $0,0.25,0.5$, 0.75 , and 1 , respectively. At the end of the test, the axial strain reaches up to $12 \%$, when the suction is stabilized, and the test is completed. It is reasonably verified that the shearing process accords with the test conditions that the water and gas phase of unsaturated soil move slowly and the mutation is small. During the whole test, the valve at the drainage hole on the instrument base is closed, with the air pressure unchanged and the pore water pressure changing continuously.

However, some errors of control of specimen deformation still exist, because there are bubbles in the water filled with hydraulic bag connected to the hydraulic loader, and the loading system will produce its own compression deformation with the increase of loading pressure. Therefore, the cuboid steel samples are used to calibrate $\varepsilon_{2}$ and $\varepsilon_{3}$ deformations. The deformation measured by the calibration of steel sample is subtracted from the test data to correct the volume variation errors caused by the instrument loading system itself.

\section{RESULTS AND ANALYSIS OF ISOTROPIC CONSOLIDATION TESTS Soil-water characteristic curves under stress free conditions}

The relationship between water content, saturation, and initial suction under stress-free conditions is shown in Figure 3. When the dry density is constant, the relation curves of the matrix suction with water content and saturation are similar to each other; that is, $s_{0}$ decreases with the increase of $w$ and $S_{\text {ro }}$, and all of them are composed of steepness and gentle descent. Taking $w=16.1 \%$ and $S_{\mathrm{ro}}=43 \%$ as the bound, when $w \geq 16.1 \%$ and $S_{\mathrm{ro}} \geq 43 \%$, both of them decrease slowly with the increase of $w$ and $S_{\text {ro }}$ and when $w<16.1 \%$ and $S_{\mathrm{ro}}<43 \%$, both of them drop rapidly with the increase of $w$ and $S_{\text {ro. }}$. The relation curve of Figure 3 shows that the change of suction is more sensitive when the water content is small $(w<16.1 \%)$, and the change of suction is slow when the water content is larger $(w \geq 16.1 \%)$. This is because the water content is small; the structure has not been disturbed or changed; the pore size and connectivity in the soil are good, and the variation of suction is more sensitive, but with the increase of water content, the structure is relatively weak, and the bonding strength among particles decreases. The cementation in the soil skeleton will be weakened, leading to the change of the pore size and the connected state of the soil, and the slow change of the suction (Chen et al., 2011; Xie et al., 1999; Xie et al., 1999; Shao et al., 2004; Shao et al., 2014; Dang et al., 2001).

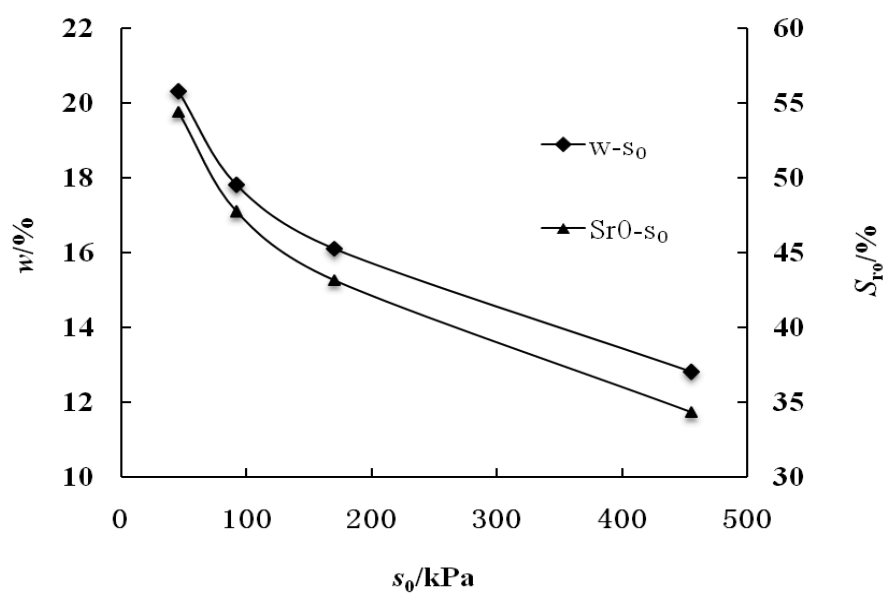

Fig. 3. Soil-water characteristic curves under stress free conditions.

\section{Suction variation characteristics}

After isotropic consolidation, the moisture content remains unchanged, but with the compression of the sample volume, the soil subsidence can be accurately measured by a high-precision axial displacement sensor; that is, the porosity ratio of the soil can be accurately calculated. Therefore, the saturation of soil with isotropic consolidation can 
be obtained. Figure 4 shows the relationship between saturation $S_{\mathrm{rc}}$ and suction $S_{\mathrm{c}}$ of unsaturated soils with isotropic consolidation. At different net mean stress $p, s_{\mathrm{c}}$ decreases with the increase of $S_{\mathrm{rc}}$; when $s_{\mathrm{c}}$ is constant, the $S_{\mathrm{rc}}-S_{\mathrm{c}}$ curve moves up with the increase of $p$, indicating that the larger the $p$ is, the higher the $S_{\mathrm{rc}}$ will be, because when the $p$ rises, the size and connectivity of the pore will be changed greatly. At the same time, Figure 4 also shows that the net mean stress $p$ has a certain influence on the soil-water characteristic curve of unsaturated soils.

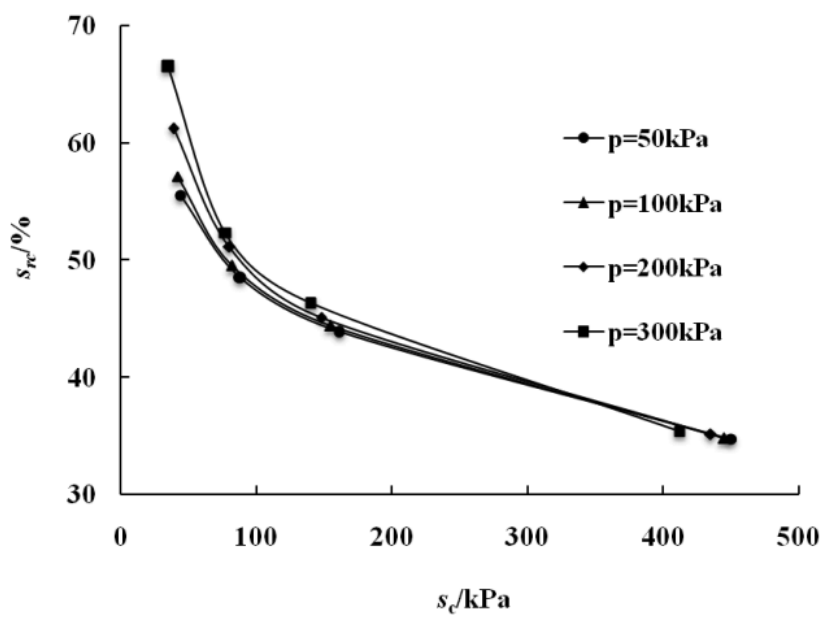

Fig. 4. Relationship curves between saturation and suction with isotropic consolidation.

\section{Characteristics of Suction Yield}

The volume of unsaturated soil will change after isotropic consolidation. In this paper, the porosity ratio of the sample $e_{\mathrm{i}}$ is used to express the volume change of the sample. The relationship between void ratio $e_{\mathrm{i}}$ and suction $s_{\mathrm{c}}$ of unsaturated soils with different initial suction after isotropic consolidation under the same net average stress $p$ can be shown in Figure 5. The $e_{\mathrm{i}}-s_{\mathrm{c}}$ is located on two intersecting lines, under different net mean stress $p, e_{\mathrm{i}}$ decreases with the increase of $s_{\mathrm{c}}$, which indicates that the suction has a certain effect on the volume change of soil. The suction corresponding to the intersection point in Figure 5 is taken as yield suction $s_{\mathrm{p}}$. The intersection points are located on the same vertical line, which indicates that the yield suctions of unsaturated soil with different initial suctions are equal under different net mean stresses. In front of the intersection point, the slope of the straight line goes down with the rise of $p$, and the straight lines are almost parallel to a straight line after the intersection point, which indicates that the increase of the net average stress has a great influence on the bulk deformation of unsaturated soil before the yield point. After the yield point, suction plays a major role in the bulk deformation of unsaturated soil.

In Figure 5, the vertical line intersects the abscissa $s_{\mathrm{c}}$ at $90 \mathrm{kPa}$, which indicates that, under different net mean stress conditions, the yield suctions $s_{\mathrm{p}}$ after being isotropically consolidated are all equal to $90 \mathrm{kPa}$. Alonso et al. (1990) proposed the yield condition of suction increase is $s=s_{0}=$ const, where $s_{0}$ is the largest suction that soil has ever suffered in history. However, the initial suctions of samples tested in this paper are 455, 170, 92, and $46 \mathrm{kPa}$, respectively; after isotropic consolidation under the different net mean stresses, the suction $s_{\mathrm{c}}$ decreases with the increase of saturation $S_{\mathrm{rc}}$. According to the yield condition of suction increase proposed by Alonso et al. (1990), the maximum suction that the specimen has ever suffered is the initial suction $s_{0}$, and the yield suction in this test is equal to $90 \mathrm{kPa}$ (not the initial suction of the sample), indicating that the yield condition of suction increase proposed by Alonso et al. (1990) is not applicable to unsaturated intact loess of this paper. 


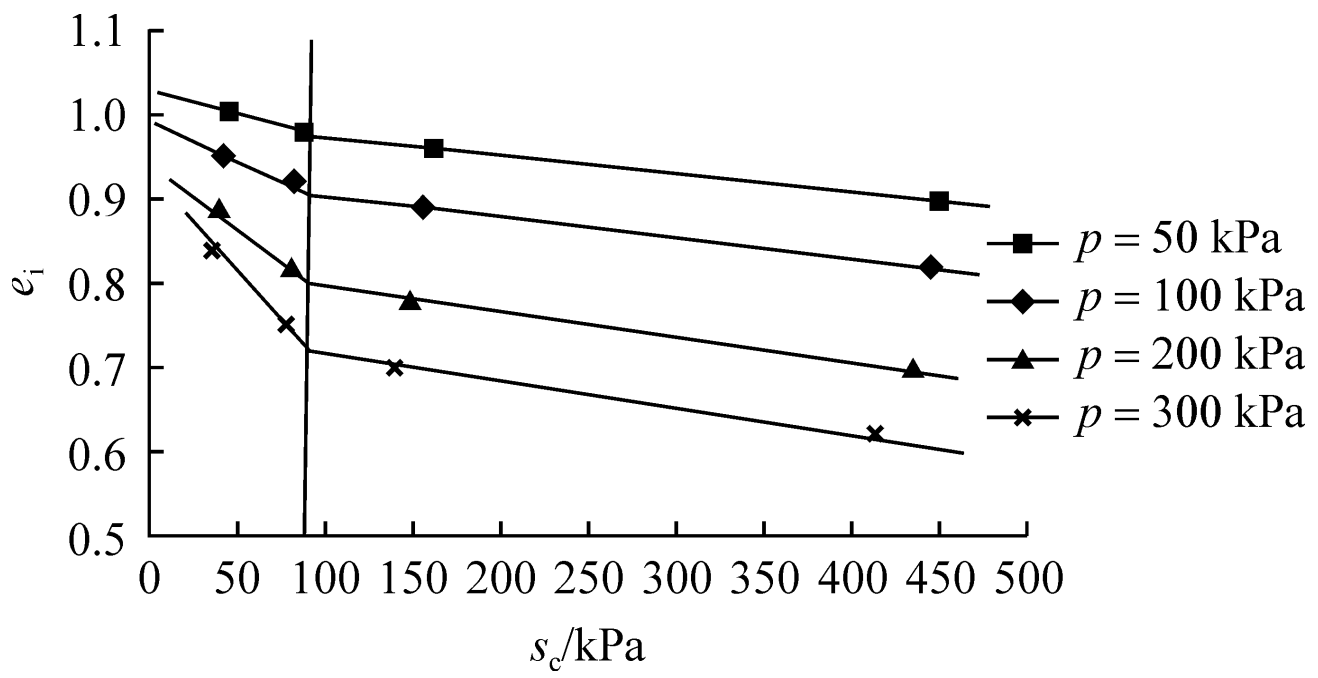

Fig. 5. The curves between void ratio $e_{\mathrm{i}}$ and suction $s_{\mathrm{c}}$ after isotropic consolidation.

\section{Characteristics of Stress Yield}

After isotropic consolidation, for the unsaturated soil with the same initial suction, the compression curves of the void ratio $e_{\mathrm{i}}$ and $p$ under different net mean stresses are shown in Figure 6. When the consolidation of unsaturated soil is completed, the volume shrinkage of the sample occurs with the compression and discharge of the pore gas in the soil. Under the condition of different initial suction, the pore ratio $e_{\mathrm{i}}$ decreases with the increase of the net mean stress $p$; when $p$ is constant, $e_{\mathrm{i}}$ decreases with the increase of $s_{0}$. The net mean stress corresponding to the intersection of the $e_{\mathrm{i}}-\lg p$ curve in Figure 6 is the isotropic compressive yield stress $p_{\mathrm{sc}}$. As the $s_{0}$ increases, the intersection point moves to the lower right, indicating that the $p_{\text {sc }}$ increases with the increase of $s_{0}$. The yield suctions and yield net mean stresses determined in Figures 5 and Figure 6 are shown in Table 2, the yield points in Figure 6 are plotted on the $p-s$ plane, the LC curve is obtained by these yield points, and $s=s_{\mathrm{p}}=$ const $=90 \mathrm{kPa}$ is drawn into the SI yield curve, as shown in Figure 7. It can be seen from Figure 7 that when $p$ increases or $s$ decreases, the points on the left side of the LC curve reach the LC curve, then yield occurs. And the LC curve is called the load-collapse yield line. The intersection point between the LC curve and the $p$-axis $(s=0)$ is the yield stress of the saturated soil. To describe the volumetric change yield behavior of unsaturated soils, two yield lines, namely, LC and SI curves are required on the $p$-s plane (Alonso et al., 1990). The two curves and the areas surrounded by coordinate axis constitute the elastic area. When the suction of the stress points in the elastic zone increases to reach the SI curve, the soil yields, and the SI curve is called the suction increase yield line. According to the yield function of saturated soil proposed by Alonso et al. (1990), the yield function of unsaturated soil can be written as follows:

$f=g=q^{2}+M^{2} p^{\prime}\left(p^{\prime}-p_{0}^{\prime}\right)$

where:

$q$ : The generalized shear;

$p^{\prime}$ : The average soil skeleton stress, $p^{\prime}=p+S_{\mathrm{r}} s$;

$M$ : The slope of the critical state line on the plane $p^{\prime}-q$;

$p_{0}^{\prime}$ : The yield stress of unsaturated soil with suction of $s$. 


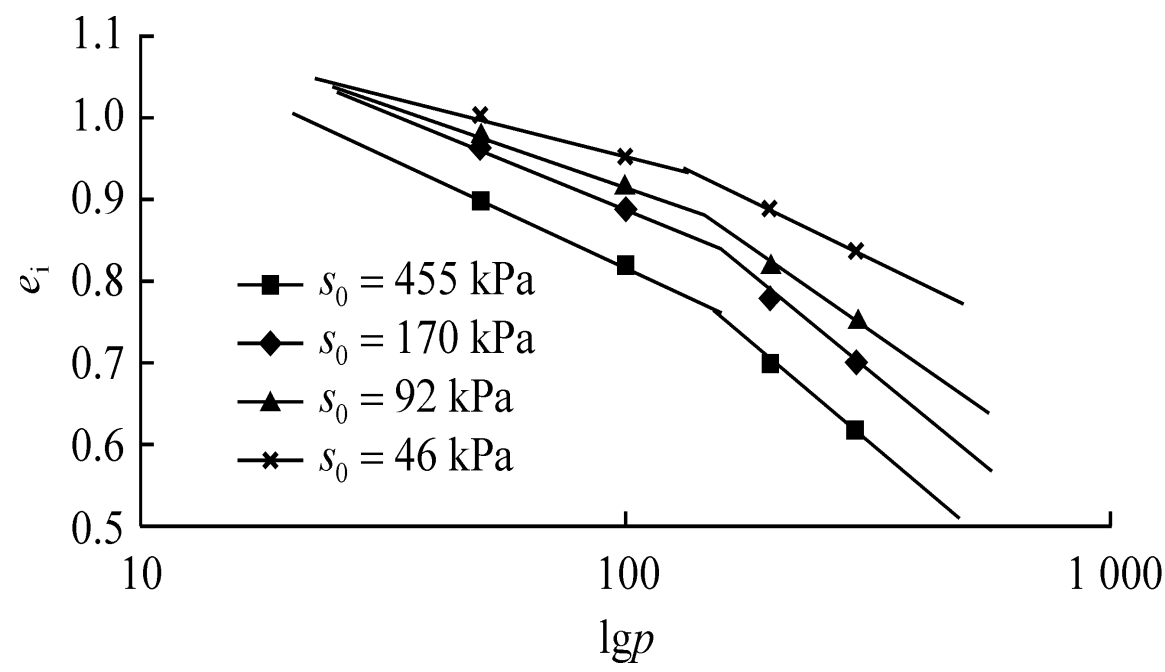

Fig. 6. Isotropic consolidation compression curve under different initial suction.

Table 2. Soil parameters related to isotropic consolidation tests.

\begin{tabular}{|c|c|c|}
\hline $\boldsymbol{s}_{\mathbf{0}}(\mathbf{k P a})$ & $\boldsymbol{p}_{\mathbf{s c}}(\mathbf{k P a})$ & $\boldsymbol{s}_{\mathbf{p}}(\mathbf{k P a})$ \\
\hline 46 & 178 & 90 \\
\hline 92 & 192 & 90 \\
\hline 170 & 198 & 90 \\
\hline 455 & 208 & 90 \\
\hline
\end{tabular}

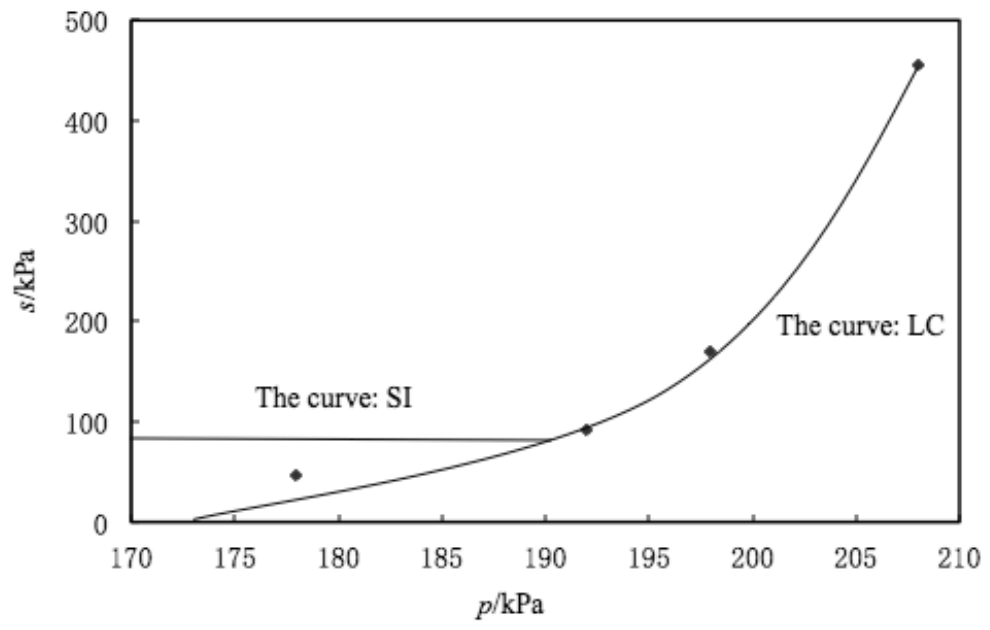

Fig. 7. Yield loci for the compacted loess in the $p$-s plane: LC and SI. 


\section{THE RESULTS AND ANALYSIS OF SHEAR TESTS}

\section{Stress-strain relationship under different $b$ values}

Figure 8 shows curves of the generalized shear stress-generalized shear strain for unsaturated soil under different $b$ values. In this paper, the generalized shear formula is as follows:

$$
q=\frac{1}{\sqrt{2}} \sqrt{\left(\sigma_{1}-\sigma_{2}\right)^{2}+\left(\sigma_{2}-\sigma_{3}\right)^{2}+\left(\sigma_{3}-\sigma_{1}\right)^{2}}
$$

where:

$q$ : The generalized shear;

$\sigma_{1}$ : Net large principal stress;

$\sigma_{2}:$ Net intermediate principal stress;

$\sigma_{3}:$ Net confining pressure.

It can be seen from Figure 8 that (1) the initial suction $s_{0}$ is the same; with the increase of net confining pressure $\sigma_{3}$, the strength of soil increases correspondingly, and the strength of soil failure increases accordingly. $s_{0}$ and $\sigma_{3}$ are constants; the $q-\varepsilon_{\mathrm{s}}$ relation curve moves up with the increase of $b$ value; that is, under the same generalized shear strain, the strength of soil rises with the increase of $b$ value. (2) As shown in Figure 8 (a) and (c), $s_{0}$ and $\sigma_{3}$ are constants; when $\varepsilon_{\mathrm{s}}$ is small, the $q-\varepsilon_{\mathrm{s}}$ curves of $b=0$ are crossed with other curves, and the slope of the initial section is the steepest, because when $\sigma_{3}$ is smaller $\left(\sigma_{3} \leq 100 \mathrm{kPa}\right)$ and $b=0$, the initial volumetric change of unsaturated soil is very slow. At the same time, if the initial suction $s_{0}$ is different, the trend of curve is similar when $b=0$, which indicates that $s_{0}$ has little effect on the strain of the soil at the beginning of shear; this is because $s_{0}$ has not yet affected the structure of the soil at the beginning of shear. (3) Under different experimental conditions, $q-\varepsilon_{\mathrm{s}}$ curves exhibit a hardening type; when $s_{0}$ and $\sigma_{3}$ are constants, the degree of hardening increases with the growth of $b$ value; when $s_{0}$ and $\sigma_{3}$ are not the same, the degree of hardening develops with the increase of $s_{0}$ and $\sigma_{3}$. This is due to the fact that the structure of unsaturated intact loess decreases with the increase of $s_{0}$ and $\sigma_{3}$ after isotropic consolidation; when $\sigma_{3}$ is greater, the soil particles arrangement varies greatly, the bonding strength among soil particles becomes slower, and the structural failure of loess will grow larger after consolidation; the decrease of the suction of the soil after isotropic consolidation may reduce the structural stability of the soil skeleton. Moreover, the initial moisture content is smaller (that is, the initial suction $s_{0}$ is greater); the soil structure stability will decline sharply after compression. Thus, with the increase of initial suction $s_{0}$ and the net confining pressure $\sigma_{3}$, the structural of the soil decreases, and the weakly structural loess exhibits strain hardening characteristics (Chen et al., 2011; Xie et al., 1999; Xie et al., 1999; Shao et al., 2004; Shao et al., 2014; Dang et al., 2001). 


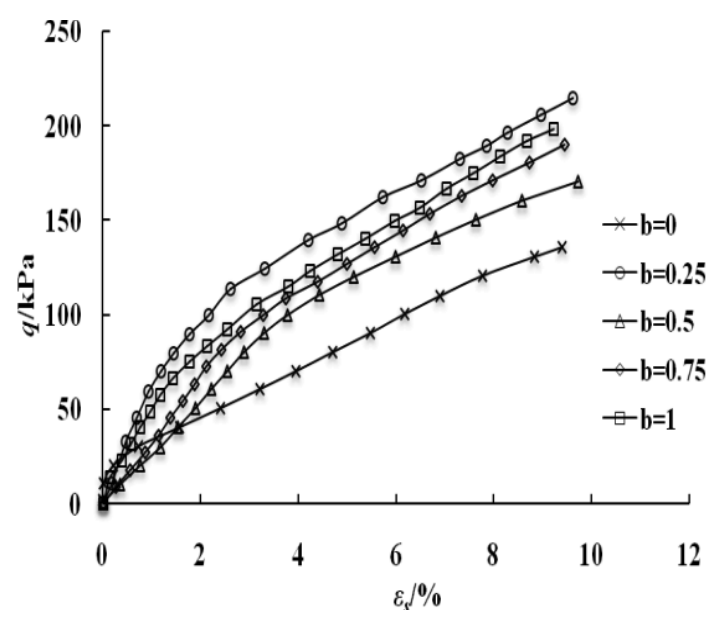

(a) $s_{0}=46 \mathrm{kPa}, \sigma_{3}=100 \mathrm{kPa}$

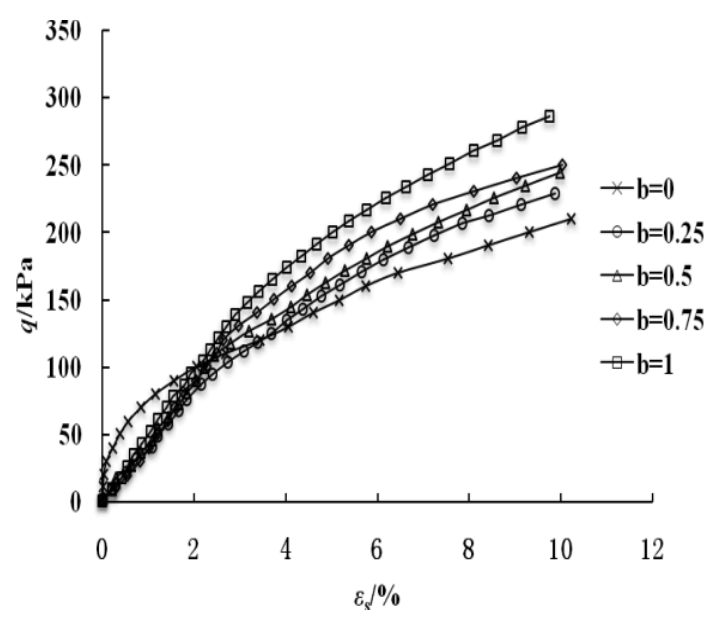

(c) $s_{0}=455 \mathrm{kPa}, \sigma_{3}=100 \mathrm{kPa}$

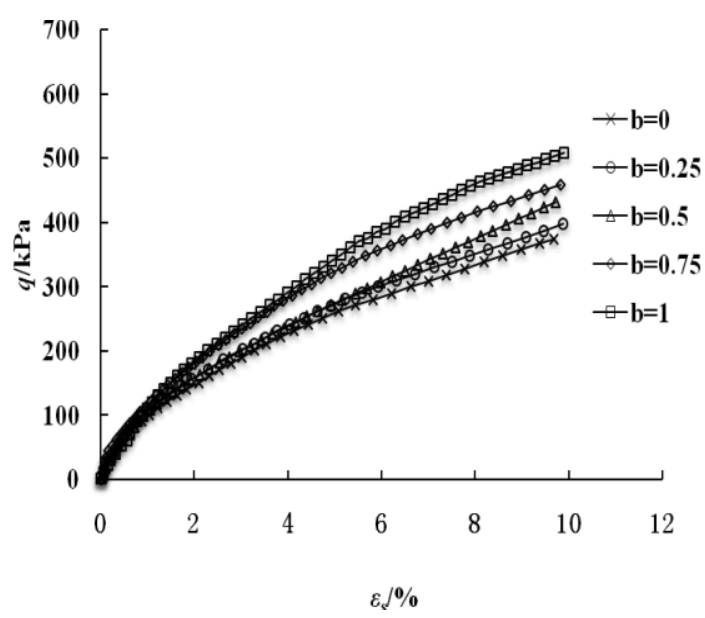

(b) $s_{0}=46 \mathrm{kPa}, \sigma_{3}=300 \mathrm{kPa}$

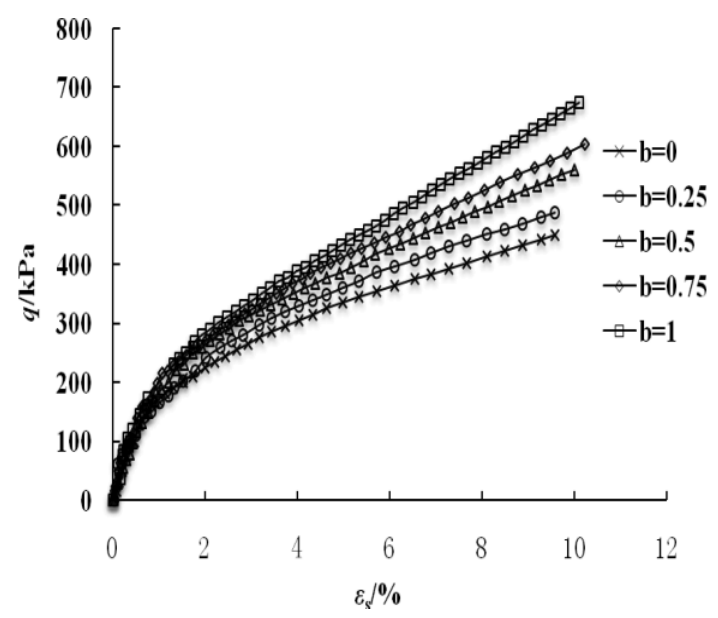

(d) $s_{0}=455 \mathrm{kPa}, \sigma_{3}=300 \mathrm{kPa}$

Fig. 8. $q-\varepsilon_{\mathrm{s}}$ relationship curves under different intermediate principal stress ratio $b$.

Figure 9 shows the generalized shear stress-generalized shear strain curves of soils with water content of $20.3 \%$ and 12.8\% under no suction. Comparing Figure 9 (a) with 8 (b), Figure 9 (b) with 8 (d), when the net confining pressure $\sigma_{3}=300 \mathrm{kPa}$, under the measuring suction and no suction conditions, the differences of shear strength $\Delta q_{1}$ and $\Delta q_{2}$ of soils with moisture content of $20.3 \%$ and $12.8 \%$ are listed in Table 3. It can be seen from Figure 9 and Table 3 that the shear strength of the soil under no suction is less than that under the measured suction, and $\Delta q_{1}>\Delta q_{2}$, indicating that the magnitude increase of shear strength of the soil with $20.3 \%$ water content is larger than that with $12.8 \%$ water content. That is, the shear strength of unsaturated soil increases with the increase of suction, and the increased amplitude under low suction is greater than that under high suction. This is because the matrix suction can promote the effective stress among the soil particles, so that the strength of the soil is relatively raised, and when the moisture content is high, the suction has a great impact on the strength of soil, whereas when the moisture content is lowered, the suction has little influence on the strength of soil. 


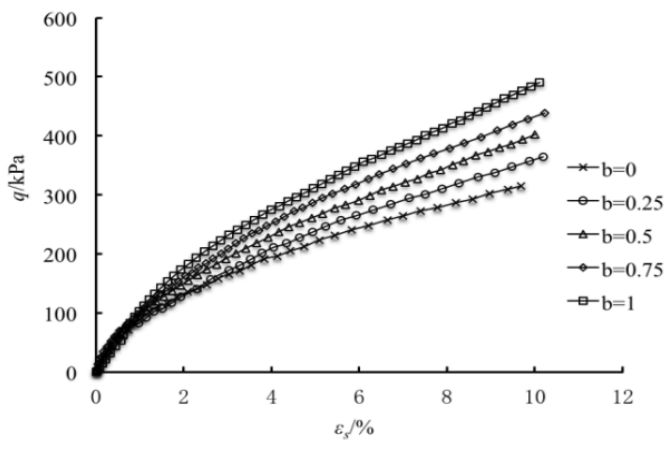

(a) $w=20.3 \%, \sigma_{3}=300 \mathrm{kPa}$

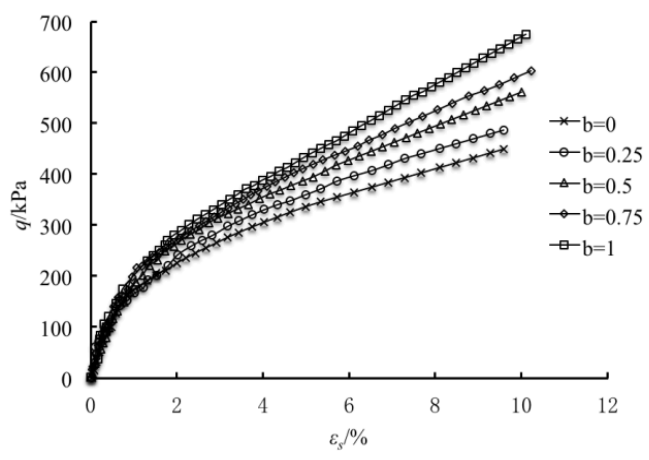

(b) $w=12.8 \%, \sigma_{3}=300 \mathrm{kPa}$

Fig. 9. $q-\varepsilon_{\mathrm{s}}$ relationship curves under zero suction.

Table 3. The soil shear strength difference.

\begin{tabular}{|c|c|c|}
\hline $\boldsymbol{b}$ & $\Delta \boldsymbol{q}_{\mathbf{1}}(\mathbf{k P a})$ & $\Delta \boldsymbol{q}_{\mathbf{2}}(\mathbf{k P a})$ \\
\hline 0.00 & 60 & 25 \\
\hline 0.25 & 40 & 30 \\
\hline 0.50 & 40 & 30 \\
\hline 0.75 & 30 & 15 \\
\hline 1.00 & 100 & 65 \\
\hline
\end{tabular}

\section{Stress-strain relationship under the same $b$ value}

Figure 10 shows a curve for the generalized shear stress-generalized shear strain of unsaturated soil under the same $b$ value; it can be seen from Figure 10, (1) when the $b$ value is constant, the strength of soil increases correspondingly with the rise of net confining pressure $\sigma_{3}$, and the strength of soil failure will be raised accordingly. (2) When $\sigma_{3}$ and $b$ are constant, and the $\varepsilon_{\mathrm{s}}$ is relatively smaller, the strength of the soil increases with the increase of $s_{0}$. If $\varepsilon_{\mathrm{s}}$ is large (over $6 \%$ ), except for $s_{0}=455 \mathrm{kPa}$, and the other curves are crossed, it can be found that when $\sigma_{3}$ and $b$ value are the same, and $s_{0}<455 \mathrm{kPa}$, the values of strength are approximately equal when the soil is close to failure. This is due to the fact that when $s_{0}$ is small, the shear stress will have a great impact on the structure of the soil during the true triaxial shear process.

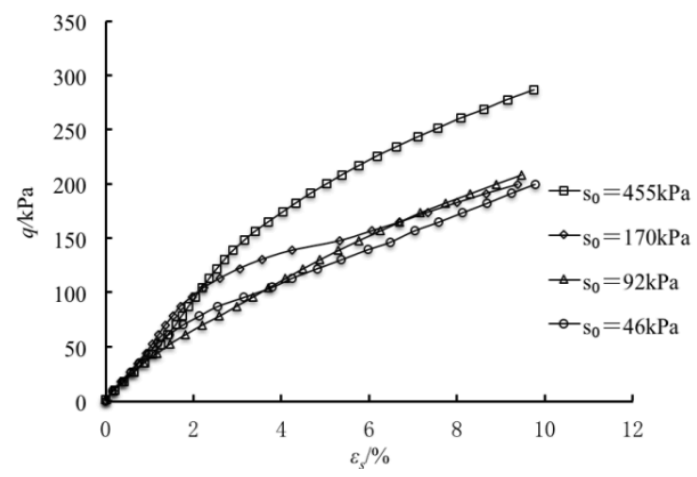

(a) $\sigma_{3}=100 \mathrm{kPa}, b=0.5$

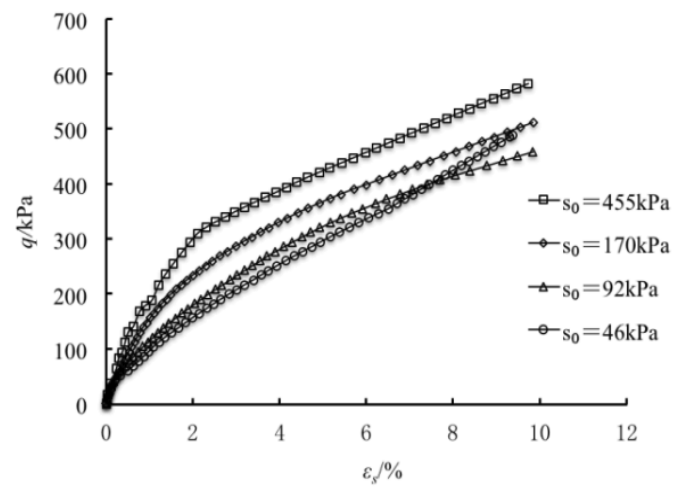

(b) $\sigma_{3}=300 \mathrm{kPa}, b=0.5$

Fig. 10. $q-\varepsilon_{\mathrm{s}}$ relationship curves with the same $b$ value. 


\section{Variation characteristics of suction with different $b$ values}

The relationship between the suction $s_{\mathrm{f}}$ of shear failure and the different $b$ values $s_{\mathrm{f}}-b$ is shown in Figure 11; it can be seen from Figure 11, (1) when $s_{0}$ is constant, the $s_{\mathrm{f}}-b$ relationship curve increases linearly with the rise of $b$, indicating that the suction $s_{\mathrm{f}}$ of shear failure grows with the increase of $b$ value; this is because when the specimen is subjected to shear failure, the primary structure may be gradually destroyed, with the secondary structure gradually generated, and the pore connectivity of the sample changed. (2) As shown in Figure 11 (a) and (b), when the initial suction is large $\left(s_{0} \geq 170 \mathrm{kPa}\right)$, the slope of $s_{\mathrm{f}}-b$ curve increases with the increase of $\sigma_{3}$, which shows that the greater the $\sigma_{3}$ is, the faster the suction will be changed during shear failure. This is because the secondary structure of soil increases with the increase of $\sigma_{3}$ and $s_{0}$ (Chen et al., 2011; Xie et al., 1999; Xie et al., 1999; Shao et al., 2004; Shao et al., 2014; Dang et al., 2001). In the true triaxial shear process, with the development of strain, the internal particle arrangement and cementation structure of the undisturbed soil are constantly adjusted; the primary structure is gradually destroyed while the secondary structure is gradually generated. With the rise of the net confining pressure $\sigma_{3}$, the net mean spherical stress increases, with the soil particles rearranged more closely to the denser, and the cementation among the soil particles enhanced. Moreover, the structure of loess is closely related to the suction in the skeleton, and the suction can improve the structural stability of the soil skeleton. Therefore, as $\sigma_{3}$ and $s_{0}$ increase, the structure of soil may become more strengthened. At this point, the pores are well connected among the soil particles, and the suction changes faster at shear failure. (3) With the decrease of $s_{0}$, the difference of suction $s_{\mathrm{f}}$ at shear failure will become smaller and smaller under different $\sigma_{3}$. Especially when $s_{0}=46 \mathrm{kPa}$, the $s_{\mathrm{f}}-b$ curves can be basically normalized to the curve of $\sigma_{3}=100 \mathrm{kPa}$. It can be approximated that when $\mathrm{s}_{0} \leq 46 \mathrm{kPa}$, the variation of $s_{\mathrm{f}}$ with $b$ value at shear failure is basically not affected by $\sigma_{3}$. This is because the structure of soil is very weak when $s_{0}$ is small, and the influence of $\sigma_{3}$ on pore connectivity and secondary structure of soil is almost small.

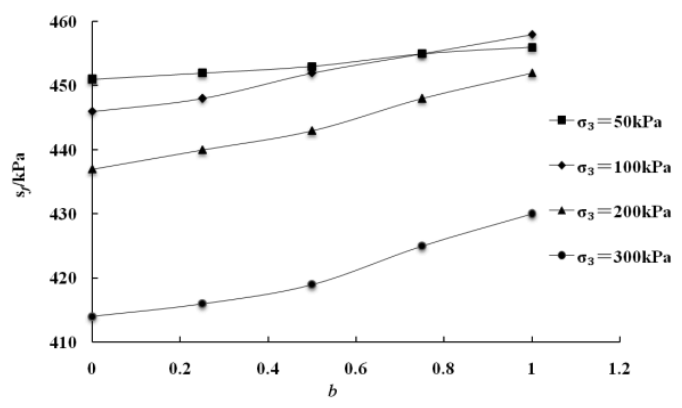

(a) $s_{0}=455 \mathrm{kPa}$

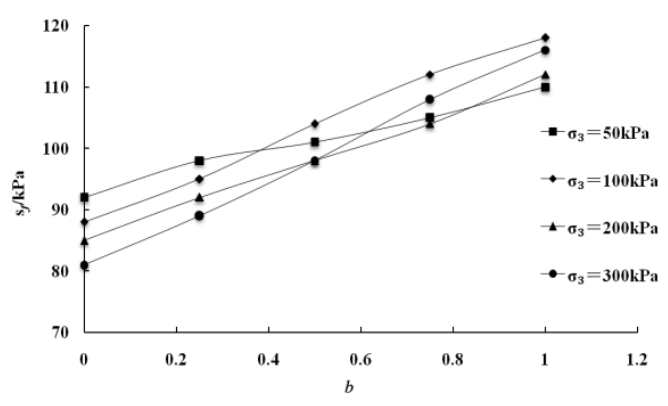

(c) $s_{0}=92 \mathrm{kPa}$

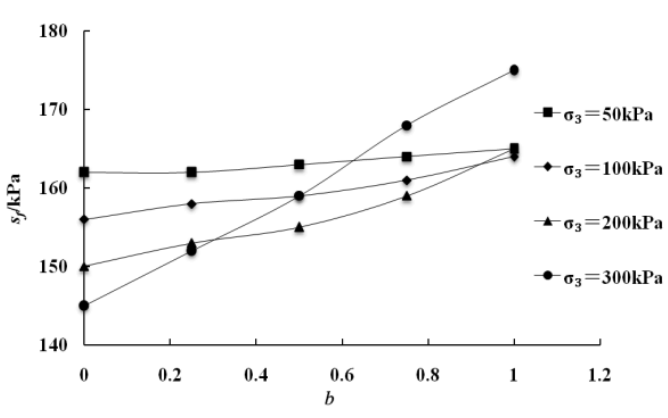

(b) $s_{0}=170 \mathrm{kPa}$

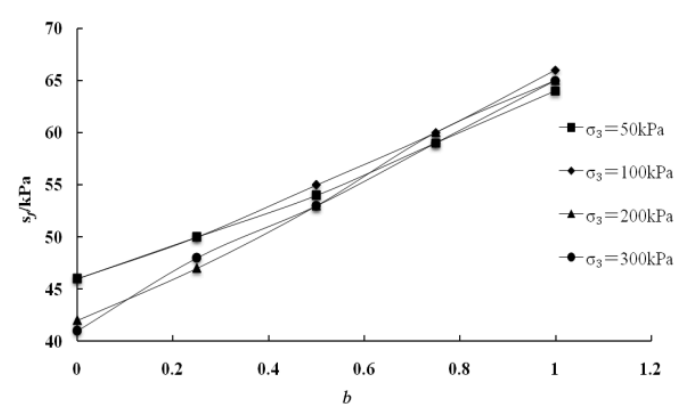

(d) $s_{0}=46 \mathrm{kPa}$

Fig. 11. Variation characteristics of suction at different $b$ values. 


\section{CONCLUSIONS}

In this paper, a series of isotropic consolidation and shear tests with different intermediate principal stress ratio $b$ under constant water content were performed on intact loess with various initial suctions by using the true tri-axial apparatus for unsaturated soil. The characteristics of suction, yield, and strength of unsaturated intact loess were studied, and the following conclusions were made:

1) When the moisture content is small, the suction decreases rapidly after isotropic consolidation, and slowly when the water content is large, but increases linearly with the increase of $b$ value after shear.

2) The yield suctions of unsaturated soils with different initial suction are identical under different net mean stresses, and the isotropic compressive yield stress increases with the rise of initial suction. The increase of net mean stress has a great effect on the bulk deformation of unsaturated soil before yield point, and the suction plays a major role in the bulk deformation of unsaturated soil after yield point.

3) The shear strength of unsaturated soil will increase with the growth of suction. The amplitude of increase at low suction is greater than that at high suction. When the net confining pressure is small $\left(\sigma_{3} \leq 100 \mathrm{kPa}\right)$ and $b=0$, the volume change of the initial section may become very slow, and the suction has little effect on the strain of the soil at the beginning of shear.

4) When the initial suction ( $s_{0} \geq 170 \mathrm{kPa}$ ) is large, the greater the net confining pressure is, and the faster the suction changes during shear failure. With the decrease of initial suction, the difference of suction at shear failure under different net confining pressures becomes smaller and smaller, especially for $s_{0}=46 \mathrm{kPa}$; the curve of $s_{\mathrm{f}}-b$ relationship can be basically normalized to curve of $\sigma_{3}=100 \mathrm{kPa}$.

\section{ACKNOWLEDGMENT}

The authors would like to acknowledge with great appreciation the support from the National Natural Science Foundation of China (51808197), the Doctorate Fund of Henan Polytechnic University (B2018-64), and the key research project of Colleges and Universities in Henan Province (19A560010).

\section{REFERENCES}

Alonso, E.E., Gens, A. \& Josa, A. A.1990. Constitutive model for partially saturated soils. Geotechnique, 40(3):405-430.

Chen, C. L., Chu, F. \& Li, L. L. 2011. Soil-water characteristics of unsaturated undisturbed loess under confined compression condition. Chinese Journal of Rock Mechanics and Engineering, 30(3): 610-615.

Chen, C. L., Zhang, D. F. \& Dong, Y. Z. 2014. Suction and mechanical behaviours of unsaturated intact loess from constant water content triaxial tests. Chinese Journal of Geotechnical Engineering, 36(7):1195-1202.

Chen, Z.H. 1999. Deformation, strength, yield and moisture change of a remolded unsaturated loess. Chinese Journal of Geotechnical Engineering, 21(1): 82-90.

Dang, J. Q. \& Li, Q. 2001. Structure strength and shear strength of unsaturated loess. Journal of Hydraulic Engineering, 7(7):79-84.

Hu, S. X., Zhou, Y. D. \& Chen, Z. H. 2005. Test study on strength character of unsaturated and undisturbed loess. Rock and Soil Mechanics, 26(4):660-664.

Liao, H. J. \& Yin, J. H. 2005. Experimental study on shear strength of unsaturated loess. In: Proc. of the 2 th national conference on unsaturated soil. Pp. 262-266. ZJN Press, Hang Zhou.

Lin, H. Z., Li, G. X. \& Yu, Y. Z. 2007. Influence of matric suction on shear strength behavior of unsaturated soils. Rock and Soil Mechanics, 28(9):1931-1936.

Li, J. Z., Hao, K. N. \& Feng, P. 2018. Research on suction equilibrium time of unsaturated reticulate red clay. KSCE Journal of Civil Engineering, 22(2): 565-571. 
Li, R. J., Liu, J. D., Yan, R., Zheng, W. \& Shao, S. J. 2014. Characteristics of structural loess strength and preliminary framework for joint strength formula. Water Science and Engineering, 7(3): 319-330.

Li, Y. L., Zhang, H. F. \& She, X. G. 2008. Experimental study of triaxial test of undisturbed unsaturated loess. Rock and Soil Mechanics, 29(10): 2859-2863.

Mei, L., Jiang, P. M. \& Li, P. 2013. Soil-water characteristic curve tests on unsaturated soil. Chinese Journal of Geotechnical Engineering, 35(Supp.1):124-128.

Miao, Q. Q., Zhang, L. \& Chen, Z. H. 2010. Experimental study of generalized SWCC of unsaturated sand and containing clay. Rock and Soil Mechanics, 31(1): 102-112.

Ng, C. W. W., Mu, Q. Y. \& Zhou, C. 2017. Effects of soil structure on the shear behaviour of an unsaturated loess at different suctions and temperatures. Canadian Geotechnical Journal, 54(2): 270-279.

Ng, C. W. W., Sadeghi, H., Hossen, S. K. B., Chiu, C. F., Alonso, E. E. \&Baghbanrezvan, S. 2016. Water retention and volumetric characteristics of intact and re-compacted loess. Canadian Geotechnical Journal, 53(8): 1258-1269.

Ng, C. W. W., Sadeghi, H. \& Jafarzadeh, F. 2017. Compression and shear strength characteristics of compacted loess at high suctions. Canadian Geotechnical Journal, 54(5): 690-699.

Shao, S. J., Luo, A. Z. \& Deng, G. H. 2009. Development of a new true tri-axial apparatus. Chinese Journal of Geotechnical Engineering, 31(8):1172-1179.

Shao, S. J., Wang, L. Q. \& Tao, H. 2014. Structural index of loess and its relation with granularity, density and humidity. Chinese Journal of Geotechnical Engineering, 36(8):1387-1393.

Shao, S. J., Zhou, F. F. \& Long, J. Y. 2004. Structural properties of loess and its quantitative parameter. Chinese Journal of Geotechnical Engineering, 26(4):531-536.

Shi, J. G., Shao, S. J. \& Tao, H. 2011. True triaxial tests and strength deformation behaviors of unsaturated soils. Chinese Journal of Geotechnical Engineering, 33(Supp.1): 85-90.

Xie, D. Y. 2001. Exploration of some new tendencies in research of loess soil mechanics. Chinese Journal of Geotechnical Engineering, 23(1):3-13.

Xie, D. Y. \& Feng, Z. Y. 2006. Consideration of some fundamental viewpoints in studying effective stress of unsaturated soils. Chinese Journal of Geotechnical Engineering, 28(2):170-173.

Xie, D. Y. \& Qi, J. L. 1999. Soil structure characteristics and new approach in research on its quantitative parameter. Chinese Journal of Geotechnical Engineering, 21(6):651-656.

Xie, D. Y. Qi, J. L. \& Zhu Y. L.1999. Soil structure parameter and its relations to deformation and strength. Journal of Hydraulic Engineering, (10):1-6.

Xing, X. L., Li, T. L. \& Fu, Y. K. 2016. Determination of the related strength parameters of unsaturated loess with conventional triaxial test. Environmental Earth Sciences, 75(1): 75-82.

Zhang, F. Z. \& Chen, X. P. 2009. Experimental study on characteristics of deformation and strength of unsaturated clay. Chinese Journal of Rock Mechanics and Engineering, 28(Supp.2): 3808-3814.

Zhan, L. T. \& Wu, H. W. 2006. Experimental study on mechanical behavior of recompacted unsaturated expansive clay. Chinese Journal of Geotechnical Engineering, 28(2): 196-201.

Submitted: $14 / 12 / 2017$

Revised: 28/03/2018

Accepted: 17/04/2018 


\title{
خصائص إجهاد الامتصاص والخضوع والمقاومة لتربة اللوس السليمة غير المثبعة استناداً على اختبارات حقيقية ثلاثية المحاور
}

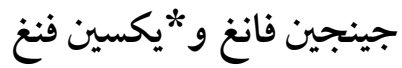

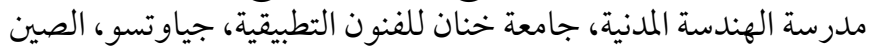

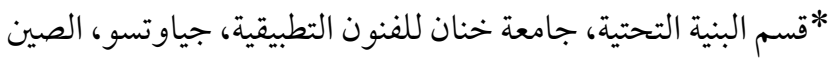

\section{الخلاصة}

يوجد القليل من التقارير حول الدراسات التجريبية عن تربة اللوس السليمة غير المشبعة بواسطة أجهزة ثلاثية المحاور حقيقية

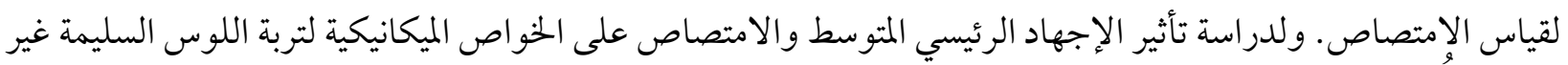

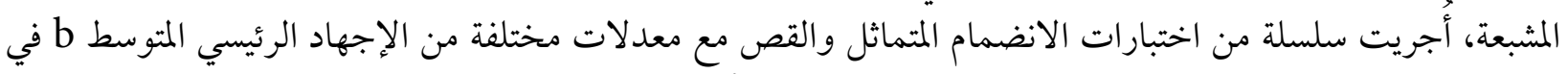

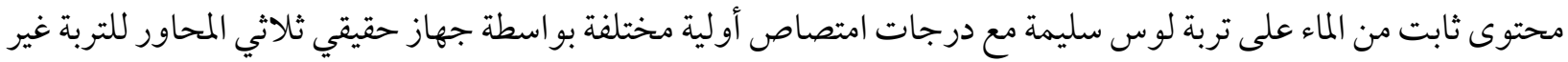

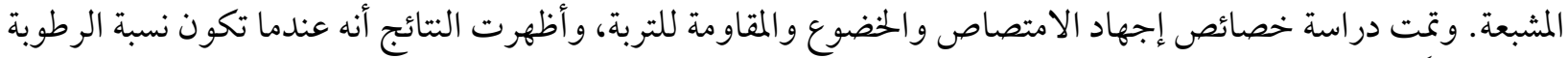

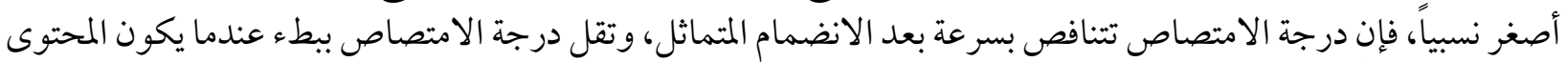

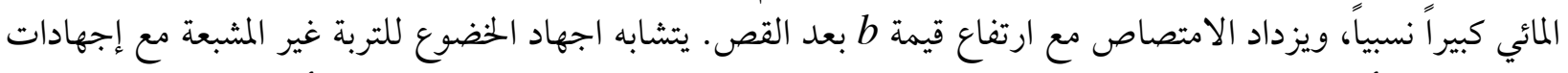

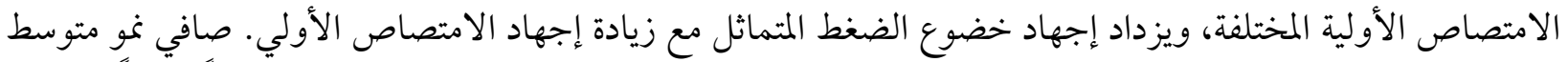

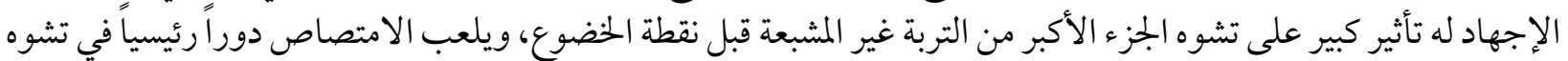

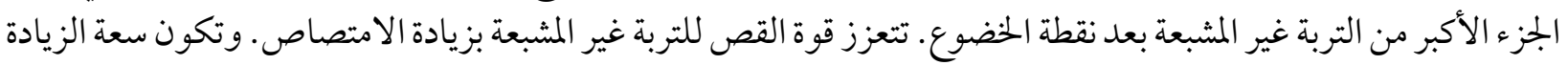

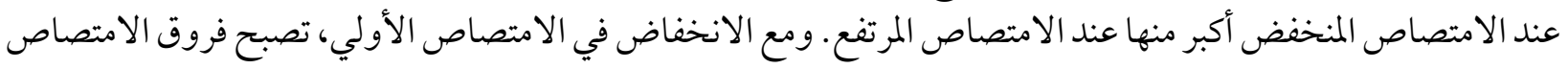
عند فشل القص أصغر بكثير تحت صافي ضغوط المن محيطة مختلفة. 